\title{
Author Correction: Quantum nanophotonics with group IV defects in diamond
}

\author{
Carlo Bradac, Weibo Gao (iD, Jacopo Forneris, Matthew E. Trusheim \& \& Igor Aharonovich
}

Correction to: Nature Communications https://doi.org/10.1038/s41467-019-13332-w, published online 09 December 2019.

The original version of this Article contained an error in the second and third sentences of the legend of Fig. 4, which incorrectly read 'Superradiant emission of $\mathrm{GeV}^{-}$centres coupled to a single-mode waveguide. The bunching signature with $g^{2}>1$ (lower left) indicates cooperative emission between two separated $\mathrm{GeV}^{-}$centres'. The correct version states 'Homodyne interferometry with a single GeV centre (top panel). Interference between $\mathrm{GeV}$ resonance fluorescence and near-resonant excitation laser light reflected in the fibre by the Bragg mirror. Varying their relative amplitude and phase, by modifying the polarization of the input laser, results in the change in line shape of the output light (mid panel) from symmetric, corresponding to destructive interference (orange) to dispersive (blue). The Hanbury Brown-Twiss interferometry measurement (bottom panel) shows $g^{2}(0)>1$ due to interference between the excitation laser and the resonant fluorescence from the single $\mathrm{GeV}$ centre. It highlights the quantum nonlinear character of the coupled GeVwaveguide system'. This has been corrected in both the PDF and HTML versions of the Article.

Published online: 14 January 2020

Open Access This article is licensed under a Creative Commons Attribution 4.0 International License, which permits use, sharing, adaptation, distribution and reproduction in any medium or format, as long as you give appropriate credit to the original author(s) and the source, provide a link to the Creative Commons license, and indicate if changes were made. The images or other third party material in this article are included in the article's Creative Commons license, unless indicated otherwise in a credit line to the material. If material is not included in the article's Creative Commons license and your intended use is not permitted by statutory regulation or exceeds the permitted use, you will need to obtain permission directly from the copyright holder. To view a copy of this license, visit http://creativecommons.org/licenses/by/4.0/.
}

(C) The Author(s) 2020 